\title{
Laboratory and Field Studies of Resistance of Crab Apple Clones to Rhagoletis pomonella (Diptera: Tephritidae)
}

\author{
W. H. REISSIG, S. K. BROWN, ${ }^{1}$ R. C. LAMB, ${ }^{1}$ AND J. N. CUMMINS ${ }^{1}$ \\ Department of Entomology, New York Agricultural Experiment Station, \\ Cornell University, Geneva, New York 14456
}

\begin{abstract}
Environ. Entomol. 19(3): 565-572 (1990)
ABSTRACT Oviposition and larval survival of Rhagoletis pomonella (Walsh) varied significantly among fruit from 25 crab apple species and clones evaluated in field and laboratory studies. In general, the relative oviposition preference and larval survival was similar in fruit infested naturally in the field and fruit tested in the laboratory. Flies oviposited more in clones with larger fruit, although this relationship was more pronounced in laboratory tests when fruit was infested by laboratory-reared flies than in fruit infested in the field by wild flies. 'Aldenhamensis,' 'Fuji,' 'Vilmorin,' Malus zumi calocarpa Rehd., and M. hupehensis (Pamp) Rehd. fruit was not infested in the field, but flies oviposited in fruit of all 25 species and clones in choice tests in the laboratory. Eggs hatched but larvae did not survive in fruit of 'Henry F. DuPont,' 'Frettingham,' 'Fuji,' 'Sparkler,' M. hupehensis, and M. zumi calocarpa. Larval mortality was very high in fruit from 'Vilmorin,' 'Sparkler,' 'NA 40298,' 'Henrietta Crosby,' 'Golden Gem,' 'Almey,' M. baccata L. (Borkh.), and M. sikkimensis (Hook.) Koehne.
\end{abstract}

KEY WORDS Insecta, Rhagoletis pomonella plant resistance, crab apples

THE APPLE MAGGOT, Rhagoletis pomonella (Walsh), which is a serious pest of apples in the eastern part of North America, is currently controlled almost exclusively with insecticides in commercial orchards. Very little work has been done to develop alternative management tactics for this pest, such as the selection of resistant apple cultivars that could be used in integrated management programs to reduce insecticide use. Although differences in oviposition preference and subsequent larval survival in various apple cultivars have been observed by various researchers, all widely grown commercial cultivars are readily infested by this pest and are considered to be susceptible. Dean \& Chapman (1973) observed that females preferred to oviposit in early-ripening, subacid varieties of apples, and larval survival was greatest in early maturing or soft-fleshed cultivars.

Only a limited amount of work has been done to study the resistance in various apple breeding lines and Malus species (such as crab apples) to oviposition and subsequent larval development of this pest. Goonewardene et al. $(1975,1979)$ screened clones of apples from a disease resistance breeding program against the apple maggot using choice and no-choice laboratory tests. They classified some of these apples as resistant to this pest, although females oviposited in most of the fruit, and larvae subsequently completed their development in apples from all but one of the clones. Neilson (1967) reported that although females oviposited in fruit of the Siberian crab (Malus baccata (L.) Borkh.)

\footnotetext{
' Horticultural Sciences Department, New York State Agricultural Experiment Station, Geneva, N.Y. 14456.
}

in the field, no larvae emerged when the fruit was collected and subsequently held in the laboratory. He showed that caged females in the laboratory readily infested most varieties of crab apple which were rarely infested in the field, but no larvae survived in crab apples of $M$. sikkimensis (Hook.) Kochae, M. toringoides Hughes, 'Henry F. DuPont,' 'Henrietta Crosby,' or 'Almey.' Pree (1977) expanded this laboratory study and identified an additional variety, 'Morden 455,' which was resistant to larval development. He also found that crab apple resistance was correlated with total phenol content, and the addition of $1,000 \mathrm{ppm}$ of any of the phenolic acids, gallic, tannic, and $o$-coumaric acids, quercetin, naringen, and d-catchin to an artificial laboratory diet prevented larval development.

In this study, we measured the oviposition and subsequent larval development and survival of apple maggot in various crab apples collected from the field at various stages of maturity and exposed in the laboratory to caged gravid females from a laboratory-reared colony of flies. We then compared the results of this laboratory study to oviposition and larval survival occurring in the field when these same crab apples were exposed to natural populations in an unsprayed orchard.

\section{Materials and Methods}

Test Orchard. The parentage or origin and approximate fruit maturation date of the crab apple clones evaluated in this study are shown in Table 1. All fruit was collected from trees planted in 1969 in an orchard at the New York State Agricultural 
Table 1. Complete name, parentage or origin, and date of fruit maturity of tested crab apple clones and species

\begin{tabular}{|c|c|c|}
\hline Clone & Parentage or origin & Date of maturity \\
\hline $\begin{array}{l}\text { Aldenhamensis } \\
\text { Almey }\end{array}$ & $\begin{array}{l}\text { Malus } \times \text { purpurea } \\
\text { M. baccata (L.) Borkh. } \times \text { M. pumila } \\
\text { var. niedswetskiana }\end{array}$ & - \\
\hline Antonovka Mitchurin & P1295282 & August \\
\hline Beauty & Malus $\times$ M. robusta (Carr.) Rehd. OP & $1-15$ October \\
\hline Dolga & Malus $\times$ M. robusta OP & September \\
\hline Frettingham & PI307689 from Holland & $1-15$ October \\
\hline Fuji & M. sieboldiia (Regel) Rehd. & $1-15$ October \\
\hline Golden Gem & M. prunifolia (Willd.) Borkh. & - \\
\hline Henrietta Crosby & $\begin{array}{l}\text { Malus } \times \text { M. arnoldiana (Rehd.) Sarg. (bac } \times \text { flor) } \times \text { M. pumila } \\
\text { var. niedswetskiana }\end{array}$ & - \\
\hline Henry F. Dupont & Malus $\times$ M. arnoldiana $\times$ M. purpurea (Barbier) Rehd. & $1-15$ October \\
\hline M. baccata 3552 & Unknown & - \\
\hline M. hupehensis & U.S. National Arboretum & 1-15 October \\
\hline M. sikkimensis & $\begin{array}{l}\text { Bundesforschungsanstalt } \\
\text { für Gartenbaulische } \\
\text { Pflanzenzuchtung, FRG }\end{array}$ & September \\
\hline M. zumi calocarpa & M. sieboldii (from Mrs. Sullivan) & $15-30$ October \\
\hline NA 40298 & U.S. National Arboretum & 1-15 October \\
\hline NY 493 & Henrietta Crosby OP & - \\
\hline Pioneer Scarlet & $\begin{array}{l}\text { Unknown seedling from } \\
\text { Brooks Alta Canada }\end{array}$ & September \\
\hline Redfield & $\begin{array}{l}\text { Wolf River } \times \text { M. pumila } \\
\text { var. niedswetskiana }\end{array}$ & 1-15 October \\
\hline $\begin{array}{l}\text { Rosedale } \\
\text { Sparkler }\end{array}$ & $\begin{array}{l}\text { M. platycarpa Rehd. PI20322 } \\
\text { M. pumila Mill var. niedswetskiana }\end{array}$ & August \\
\hline & Hopa OP & 1-15 October \\
\hline Sikora & M. prunifolia (Willd.) Borkh. PI205559 & August \\
\hline Transcendent & Unknown & September \\
\hline Vilmorin & M. yunanensis (Franch.) Sichneid. & 15-30 Octaber \\
\hline Virginia Crab & Unknown & September \\
\hline Whitney & Unknown & September \\
\hline
\end{tabular}

Experiment Station in Geneva. Single trees of each crab apple clone were planted randomly within the orchard, which consisted of a total of about 200 different clones. Clones were grafted to MM.106 clonal rootstocks planted 3 by $9 \mathrm{~m}$ apart. The trees varied considerably in size, ranging from 1.5 to 3.0 $\mathrm{m}$ high. The test orchard had received only sporadic treatments of insecticides during several seasons before this work was done and was heavily infested with apple maggot. During 1986, when these tests were conducted, the orchard was treated with a standard fungicide schedule but was sprayed only once with the insecticide azinphosmethyl $(0.3$ $\mathrm{g}$ [Al]/liter) on 29 May at petal fall. This spray was applied to control early-season fruit-feeding insect pests and according to previous observations would have had no effect on apple maggot adults, which began to emerge in late June after the residue of the early spray was no longer effective. To prevent natural infestation of fruit used in laboratory studies, 2-3 branches on each selected tree containing 25-50 fruit were covered with large cheesecloth bags $(61$ by $91 \mathrm{~cm}$ ) before apple maggots emerged. The open end of each bag was tied tightly around the lower portion of the branch with string to exclude flies. Whenever uninfested fruit was collected for laboratory studies, the bag was untied, apples were picked, and the bag was then refastened.

Lahoratory Oviposition Preference. All labo- ratory oviposition preference tests and larval survival tests were conducted with flies from a laboratory colony that had been reared continuously at Geneva for about 52 generations. The larvae were reared on 'Delicious' apples, and adults were maintained on an artificial diet (Neilson \& McAllan 1965). Tests were conducted with gravid females 14-21 d old. Preference tests were conducted in clear plexiglass and screen cages ( 46 by 46 by 46 $\mathrm{cm})$. The tops and sides of the cages were covered with wire mesh screen. The initial oviposition preference test was conducted on 24 June when most of the fruit was relatively immature. A single, freshly picked fruit from each of the 25 test clones was suspended $2-3 \mathrm{~cm}$ below the top of each test cage by fastening a small flexible wire to the stem of each fruit and looping it through the top wire mesh. The fruits were arranged at random in a square grid pattern so that they were distributed equidistantly around the top of the cage. Twentyfive naive gravid females that had previously been confined with males were placed in each cage and allowed to oviposit for $24 \mathrm{~h}$. Tests were conducted in a controlled environmental chamber at $21^{\circ} \mathrm{C}$ in a 16:8 (L:D) photoperiod. Each cage was considered to be a replication, so that 10 fruit of each selection were evaluated in each separate preference test in 10 separate cages. After $24 \mathrm{~h}$, the fruit was removed and the number of oviposition punc- 
tures on each fruit were counted under a binocular dissecting microscope. Up to five randomly selected oviposition punctures on each fruit were dissected with a fine pair of watchmaker's forceps to estimate the percentage of punctures containing eggs. After the first test, 10-12 mature 'Delicious' apples were placed in each of the cages, and the females were allowed to oviposit in the fruit for $24 \mathrm{~h}$. The test was repeated the next day as previously described using the females that had just been exposed to the standard apples.

Similar tests were conducted on 11 August to compare the relative oviposition preference on more mature fruit, and again on 15 January to compare oviposition on fruit that had been picked in the fall at maturity (from 21 August to 11 September) and kept in cold storage at $1^{\circ} \mathrm{C}$.

Data collected in the laboratory oviposition tests were transformed $\left(\log _{10} X\right)$, subjected to an analysis of variance (ANOVA), and means were compared with a Waller-Duncan $k$ ratio procedure $(P<0.05)$ (SAS Institute 1985). Because initial analysis showed that differences in oviposition preference were similar in naive females and those exposed previously to apples, the analysis of 20 replications were combined and are shown in Fig. 1 and 2 . The relationship between fruit diameter and oviposition in the fruit infested in the laboratory in July and August (Fig. 3 and 4) was compared with regression analysis (Minitab, from Ryan et al. 1976).

Field Oviposition Preference. To compare the differences in oviposition preference of the various clones that were exposed to natural apple maggot populations in the field, a random sample of 1525 fruit was collected in the fall from trees of each crab apple clone and a 'McIntosh' standard when the fruit was almost mature (21 August to 9 September). The fruit was brought into the laboratory and oviposition punctures were counted under a dissecting microscope. Up to five punctures were dissected on each fruit to determine the percentage of oviposition punctures containing eggs. The average number of oviposition punctures and the $95 \%$ CI ( $T$ interval, Minitab) is shown in Fig. 2 a.

The general levels of infestation on the different crab apple clones obtained in the laboratory with caged females were substantially higher than those occurring naturally in the field. Therefore, the relative oviposition preference of the crab apple clones was ranked in the laboratory and in the field according to the average number of oviposition punctures. The rankings were compared between the two laboratory preference tests in July and August, and between the laboratory tests and the field preference ratings by using a Spearman's rank correlation coefficient test (Minitab).

Laboratory Larval Survival Tests. These survival tests were conducted simultaneously with the preference tests with fruit picked on 24 June and 11 August and stored fruit on 15 January. Fifteen fruits of each clone were infested in a no-choice test in which all fruit were suspended from the top of a plexiglass frame cage as previously described for the laboratory preference tests. A slightly smaller cage ( 25 by 25 by $25 \mathrm{~cm}$ ) was used for confining 25 gravid females in these survival tests. After 24 $h$, the fruit were removed, the punctures were counted, and all 15 fruit from each clone were put on a hardware cloth rack inside a clear rectangular plastic dish ( 13 by 30 by $6 \mathrm{~cm}$ ). Each dish was filled with about $1 \mathrm{~cm}$ of water to drown mature larvae as they emerged from the infested fruit. During the test, the fruit was held at $24^{\circ} \mathrm{C}$ and $16: 8$ (L:D). Emerging larvae were counted daily and removed so that the cumulative total emergence pattern from each fruit clone could be compared.

Field Larval Survival Tests. When the fruit was mature in the field (21 August-9 September), a random sample of 15-25 crab apples was picked from each tree. Then the oviposition punctures were counted on each fruit. If the fruit had an average of $<2$ punctures; the picked fruit was infested in the laboratory, as previously described, to insure that the infestation level was sufficient to allow an adequate rating of larval survival. This infested fruit was then incubated on wire racks in an environmental chamber as previously described for the laboratory survival tests.

After the larval emergence had stopped in all of the survival tests, all of the fruit in which no larvae survived were dissected and examined to determine if eggs had hatched and the general extent of larval development and internal fruit damage.

\section{Results}

Oviposition Preference. Almost all punctures that were dissected contained at least one egg, even in those clones that were only slightly infested. Therefore, we assumed that counts of oviposition punctures were an adequate assessment of actual oviposition by apple maggot females.

Although there were large and statistically significant differences in the amount of oviposition among the different crab apples in the laboratory choice tests in July and August and the stored fruit tests in January (Fig. 1b, c; 2), all of the clones were at least slightly infested. The no-choice tests (Table 2), which were used to infest fruit for the larval survival studies, also demonstrated that none of the clones was immune to oviposition under laboratory conditions. 'Redfield,' 'Whitney,' and 'Antonovka Mitchurin' were the most preferred clones for oviposition in the laboratory, whereas the clones with smaller, harder fruit ('Sparkler,' 'Fuji,' 'Vilmorin,' M. sikkimensis, M. zumi calocarpa Rehd., and $M$. hupehensis(Pamp) Rehd.) were only lightly infested (Fig. Ib, c). In both laboratory tests, there was a significant positive relationship between fruit diameter and the average number of punctures per fruit (Fig. 3 and 4).

The same oviposition preference trends were ap- 


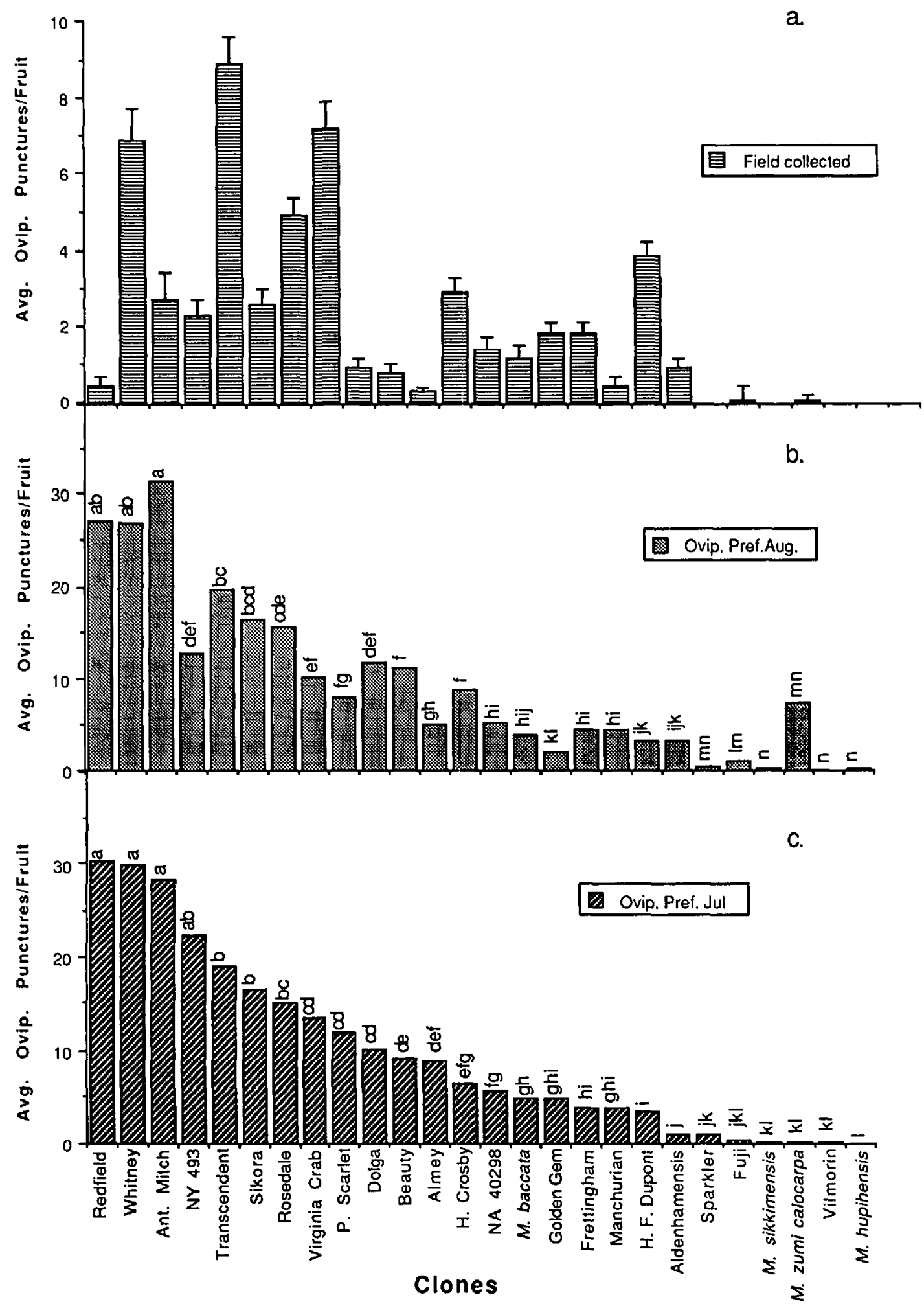

Fig. 1. Comparison of apple maggot oviposition in fruit from crab apple clones exposed to gravid females in the laboratory in choice tests or naturally infested in unsprayed trees in the field. (a) Fruit naturally infested in the field by wild apple maggot females and harvested in late August and September. (b) Fruit picked on 11 August and exposed in the laboratory to gravid laboratory-reared apple maggot females. (c) Fruit picked on 24 July and exposed in the laboratory to gravid laboratory-reared apple maggot females. Means within Fig. (b) and (c) marked with the same letters are not significantly different $(P<0.05$, Waller-Duncan $k$ ratio procedure). 


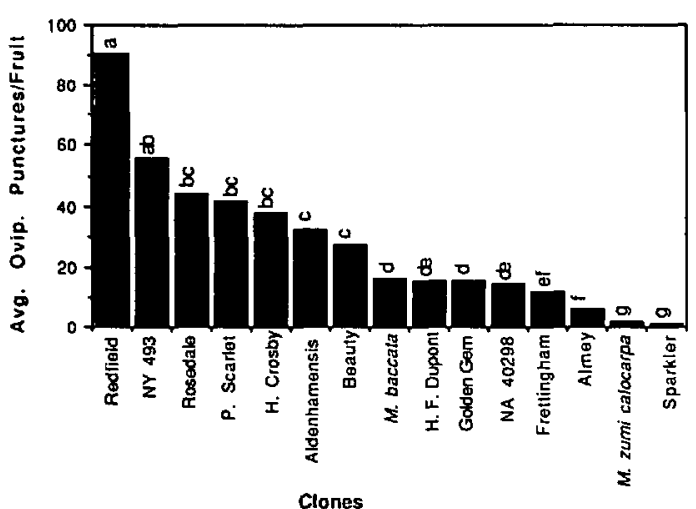

Fig. 2. Oviposition of laboratory-reared apple maggot females in laboratory choice tests in fruit from crab apple clones harvested in the fall in August and September 1986 and held in cold storage until 15 January 1987. Means marked with the same letters are not significantly different $(P<0.05$, Waller-Duncan $k$ ratio procedure).

parent in the clones when they were naturally infested in the field (Fig. 1a), although 'Redfield,' and 'Antonovka Mitchurin' were relatively less infested than they were in the laboratory. In contrast to the laboratory tests, no oviposition punctures were observed in the field-collected fruit of 'Aldenhamensis,' 'Fuji,' 'Vilmorin,' M. zumi calocar$p a$, and $M$. hupehensis. Obviously, oviposition pressure from the natural population in the field was considerably less severe than that set up in the laboratory preference tests because the most heavily infested field-collected fruit averaged fewer than nine punctures per fruit in contrast with the most heavily infested laboratory fruit, which averaged about 30 punctures per fruit. Although in fieldinfested fruit there was a significant correlation between fruit diameter and the average number of oviposition punctures $(P<0.05)$, the relationship is not as pronounced as that occurring in the laboratory when the fruit was infested by laboratory flies (Fig. 5).

Despite these differences in oviposition levels, the overall preference rankings were significantly correlated $(P<0.01)$ between the laboratory and the field. The Spearman's rank correlation coefficient between the July laboratory tests and the field observations was 0.688 , and the correlation between the August laboratory tests and the field infestation was 0.603 . As indicated in Fig. 1, the rankings in the two summer laboratory preference tests, which had a Spearman correlation coefficient of 0.923 , were virtually identical.

Larval Survival. No larvae emerged from fruit in 15 of the 26 clones infested in the laboratory in July, but fruit infested later in the season in August were somewhat more favorable for larval survival; larvae failed to emerge from only nine clones $(\mathrm{Ta}$ ble 2). Larval survival in fruit infested in the lab-

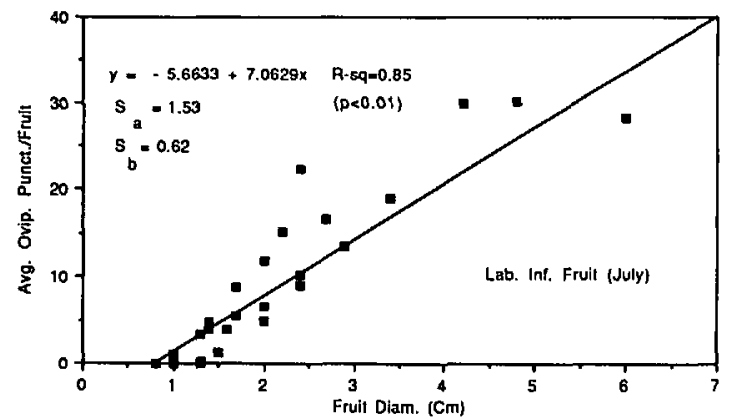

Fig. 3. Relationship between fruit diameter of crab apple clones and the average number of apple maggot oviposition punctures per fruit in laboratory choice tests conducted with fruit picked on 24 July.

oratory in August was fairly similar to that occurring naturally from field-collected fruit. Fruit from the following clones and species collected from the field late in the season and either naturally or artificially infested did not support larval development: 'Henry F. Dupont,' 'Frettingham, ' Fuji,' 'NA 40298,' 'Sparkler,' M. hupehensis, M. sikkimensis, and $M$. zumi calocarpa. Only a few larvae were reared from M. baccata L. (Borkh.), "Almey, 'Golden Gem,' 'Henrietta Cosby,' and 'Vilmorin' fieldcollected fruit. Larvae survival in the fruit infested on 15 January, after a prolonged period of cold storage, was very similar to that occurring in the August laboratory tests and in the field-infested fruit, although no larvae survived in the 'Beauty' fruit; fruit from 'Beauty' did not store well, and the soft texture and rapid decay of this fruit after it was infested probably rendered the fruit unsuitable for larval development.

The differences in the median time of emergence of surviving larvae occurring among the different clones infested in the laboratory indicate that the rate of larval development varied somewhat among different fruit (Table 2). For example,

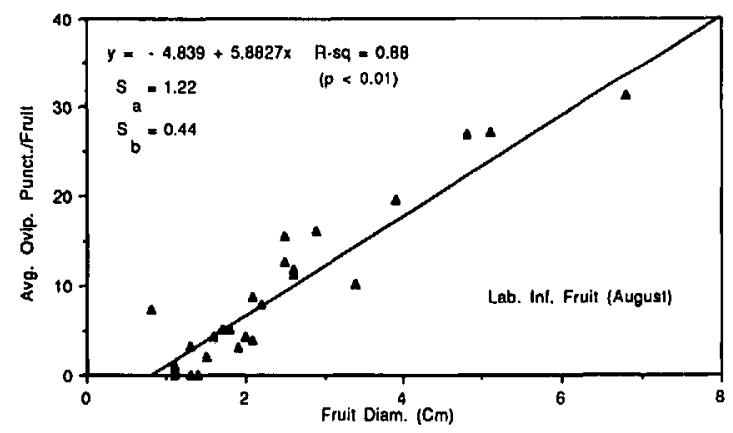

Fig. 4. Relationship between fruit diameter of crab apple clones and the average number of apple maggot oviposition punctures per fruit in laboratory choice tests conducted with fruit picked on 11 August. 


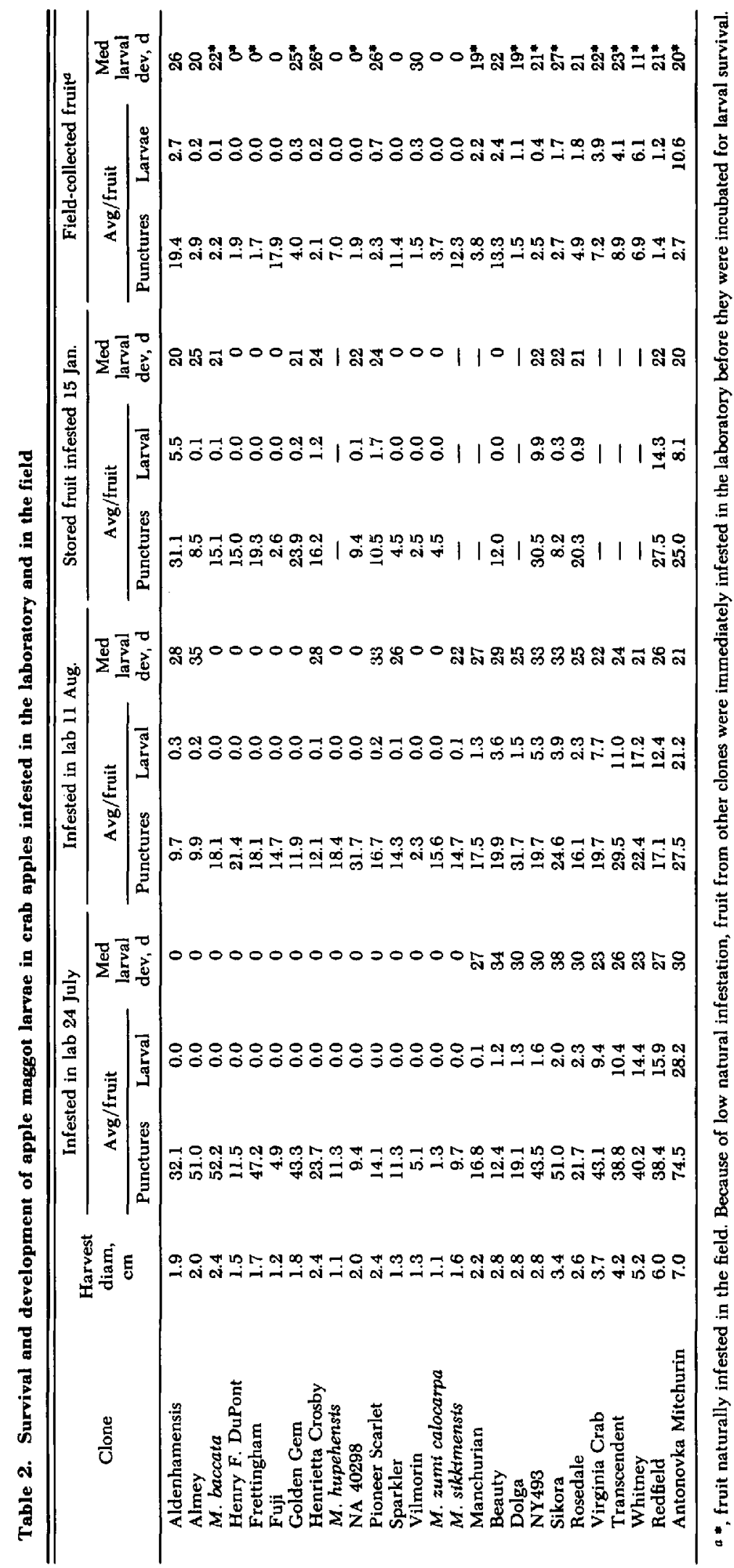


in the July laboratory tests, larvae emerged much more slowly from infested 'Sikora' fruit, in which the median larval emergence interval was $38 \mathrm{~d}$, than from 'Virginia Crab' and 'Whitney,' in which the emergence interval was only $23 \mathrm{~d}$. The same differences in larval emergence patterns also occurred in the August laboratory tests. However, in the field-collected fruit in which the time of actual oviposition could have varied considerably, the larval emergence patterns after the fruit was picked were relatively consistent except for 'Whitney,' in which the median emergence occurred only $11 \mathrm{~d}$ after the fruit was brought into the laboratory, and in 'Vilmorin,' in which the median emergence was $30 \mathrm{~d}$.

After the survival study was completed, it was difficult to determine the exact stages of larval mortality because the fruit was in relatively poor condition. However, it appeared that most of the eggs hatched in the fruit of these clones, but the subsequent larvae died during the early instars.

\section{Discussion}

Our study demonstrated that several new crab apple clones and species ('Frettingham,' 'Fuji,' $M$. hupehensis, and M. zumi calocarpa) are completely resistant to the development of apple maggot larvae, and it identified other crab apples ('Sparkler,' 'NA 40298,' and 'Golden Gem') in which larval mortality is extremely high. The survival of larvae varied somewhat among fruit from the different clones according to the stage of fruit maturity at infestation and whether or not fruit was picked and infested in the laboratory or was infested naturally and allowed to remain on the tree until maturity. The results obtained with these crab apple clones are consistent with studies previously conducted in commercial apple cultivars in which survival of apple maggot larvae varied according to the time of infestation in the field and whether or not the fruit was picked or remained on the tree (Reissig 1979).

The rankings of preference and susceptibility in the laboratory and field were obtained from fruit collected from only one or two trees of each selection because adequate replication in the experimental orchard was lacking. These selections are clones, and by definition, a clone is the aggregate of the asexual progeny of an individual. Genetic variation is fixed. However, it is likely that the characteristics of genetically identical fruit could vary somewhat among individual trees planted in different localized environments. Because of the lack of replication of trees in the test orchard used in this study, it was not possible to estimate the amount of potential variability among fruit from the same clone from replications of trees planted in the field in different microhabitats. In the future, it would be desirable to investigate the effects of environmental variability on the oviposition preference and survival of apple maggots in fruit from

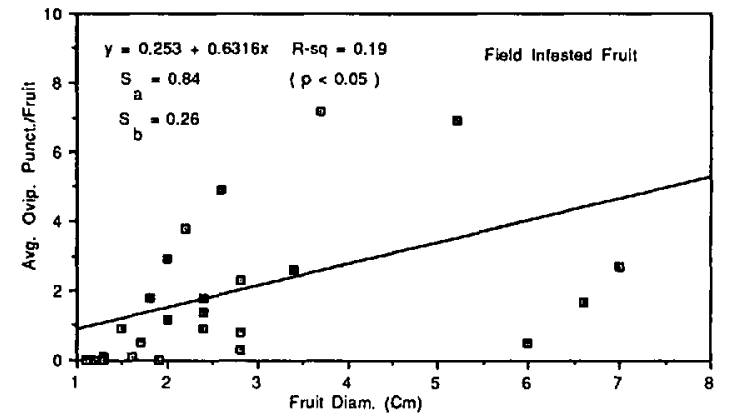

Fig. 5. Relationship between fruit diameter and the average number of apple maggot oviposition punctures per fruit in crab apple clones naturally infested in the field by wild apple maggot females.

some of these clones using fruit collected from a number of trees replicated in different orchard environments.

Although ideally, oviposition preference and fruit susceptibility to larval development should be assessed on naturally infested fruit that is allowed to remain on the tree until harvest, it may not be feasible to conduct large-scale resistance evaluation programs exclusively in the field because of the practical difficulty in establishing large, uniform populations of flies in the field in experimental orchards with replicated plantings. The laboratory techniques described in this study should be quite useful in the preliminary evaluation of the resistance of apple germplasm and for testing future breeding clones for apple maggot resistance, because larval survival and the relative oviposition preference rankings of the different clones were generally similar in fruit infested in the laboratory and in fruit infested naturally in the field by wild flies. Also, it might be quite feasible to continue to test the resistance of apple germplasm in the laboratory throughout the fall and winter months using fruit held in cold storage, because this study has indicated that larval survival in crab apples stored for several months was quite similar to that in freshly picked fruit.

However, final evaluations of apple maggot resistance should include both field and laboratory studies because of the subtle but potentially important differences in host preference and larval survival that may occur under different experimental conditions. For example, in previous laboratory tests conducted by Neilson (1967) and Pree (1977), no larvae completed their development in fruit of 'Almey, 'Henrietta Crosby,' and M. baccata. In this study, a few larvae survived in fruit of $M$. baccata and 'Henrietta Crosby' that were naturally infested in the field and in 'Almey' fruit collected at harvest and infested in the laboratory. Also, we discovered that oviposition preference and fruit size were much more strongly correlated in the laboratory tests than in fruit collected from the field, primarily because oviposition in the field was 
relatively low in several of the clones with larger fruit. Several factors could account for these discrepancies in oviposition preferences. First, since the plantings of clones were not replicated in the field orchard, the relatively low oviposition in some of the larger cultivars may have been caused by uneven population distribution of flies within the orchard. It is also possible that oviposition preferences may have been different in the laboratoryreared colony flies and the wild population. Previous studies in the laboratory (D. C. Smith, unpublished data) have shown that flies from the colony used in this study oviposited relatively more heavily in large red apples than in smaller green immature fruit, whereas wild flies preferred to oviposit in the immature apples. Presumably, because the laboratory colony of flies used in this study has been reared on mature 'Delicious' apples for many generations, a population has been selected whose preferences for physical characteristics of oviposition hosts differ from those of wild flies.

Because the apple maggot has now become established on the west coast of the United States (AliNiazee \& Brunner 1986) and continues to be a key pest influencing insecticide use in eastern North America, the future development of resistant apple cultivars would greatly aid in the overall management of this pest. However, there may be several problems in developing and marketing apple maggot-resistant apples in the future. Although there were large differences in the relative amount of oviposition occurring among the different crab apple clones evaluated (which was positively correlated with average fruit size), none of the fruit was immune to oviposition when exposed to heavy oviposition pressure from laboratory-reared flies. Neilson (1967) also found that most varieties of crab apples that were seldom infested outdoors under natural conditions were readily infested in the laboratory. However, even if the type of resistance to larval development observed in this study among the various crab apple clones can be incorporated into commercially grown apple cultivars in the future, this larval resistance may have only limited use in conventional apple production systems because of the current zero tolerance for internal damage from insects in apples. However, growers interested in producing organically grown apples or homeowners with small plantings may be willing to accept some slight internal damage from small apple maggot larvae. Resistant cultivars also may be used in conjunction with other nonchemical control measures such as trapping (Reissig et al. 1984, Prokopy 1985) for apple maggot management in types of management programs that involve low pesticide input.

\section{References Cited}

AliNiazee, M. T. \& J. F. Brunner. 1986. Apple maggot in the western United States: a review of its establishment and current approaches to management. J. Entomol. Soc. B. C. 83; 49-53.

Dean, A. W. \& P. J. Chapman. 1973. Bionomics of the apple maggot in New York. Search Agric. (Geneva, N.Y.) 3: $64 \mathrm{p}$.

Goonewardene, H. F., W. F. Kwolek, R. E. Dolphin \& E. B. Williams. 1975. Evaluating resistance of apple fruits to four insect pests. Hortscience 10: 393394.

Goonewardene, H. F., W. F. Kwolek, T. E. Mouzin \& E. B. Williams. 1979. A "no-choice" study for evaluating resistance of apple fruits to four insect pests. Hortscience 14: 165-166.

Neilson, W. T. A. 1967. Developmental and mortality of the apple maggot, Rhagoletis pomonella, in crab apples. Can. Entomol. 99: 217-219.

Neilson, W. T. A. \& J. W. McAllan. 1965. Artificial diets for the apple maggot. III. Improved, defined diets. J. Econ. Entomol. 58: 542-543.

Pree, D. J. 1977. Resistance to development of larvae of the apple maggot in crab apples. J. Econ. Entomol. 70: 611-614.

Prokopy, R. J. 1985. A low-spray apple-pest-management program for small orchards. Can. Entomol. 117:581-585.

Reissig, W. H. 1979. Survival of apple maggot larvae, Rhagoletis pomonella (Diptera: Tephritidae), in picked and unpicked apples. Can. Entomol. 111: 181187.

Reissig, W. H., R. W. Weires, C. G. Forshey, W. L. Roelofs, R. C. Lamb, H. S. Aldwinckle \& S. R. Alm. 1984. Management of the apple maggot, Rhagolet is pomonella (Walsh) (Diptera: Tephritidae) in diseaseresistant dwarf and semi-dwarf apple trees. Environ. Entomol. 13: 684-690.

Ryan, T. A., B. L. Joiner, \& B. F. Ryan. 1976. Minitab student handbook. Duxbury, New York.

SAS Institute. 1985. SAS user's guide: statistics, Version 5. SAS Institute, Cary, N.C.

Received for publication 26 January 1989; accepted 5 July 1989. 